\title{
Million Volt Microscopy and Gold Research
}

\author{
P. R. Swann and E. P. Butler
}

Department of Metallurgy, Imperial College, London

The increased penetrating power of a new million volt electron microscope has made it possible for the first time to examine specimens that are thick enough to exhibit most of the characteristic properties of bulk material. The continuous observation of structural changes made possible with this instrument has helped to elucidate the phenomena of corrosion and stress-corrosion in gold alloys containing base metals.

A million volt electron microscope manufactured jointly by Associated Electrical Industries and the Swiss company Haefely has recently been installed in the Department of Metallurgy at Imperial College. The facility is sponsored by the Science Research Council and serves universities in the South East region of England.

The primary advantage of the instrument over conventional electron microscopes is its ability to penetrate thicker specimens. This is particularly important for studying gold which, because of its high atomic number, has a transparency limit of only about 500 atoms in conventional $100 \mathrm{kV}$ instruments. In the new microscope specimens more than 3000 atoms thick can be penetrated and at this increased thickness the properties of gold and its alloys approach those of bulk material, thus enabling useful experiments to be carried out directly on specimens themselves in the electron microscope. Such in situ experiments are extremely informative because they allow continuous observations of structural changes to be made at high resolution; this not only simplifies

Fig. 1 The main operating console of the one million volt electron microscope at the Department of Metallurgy, Imperial College. The high voltage electron accelerator and generator are housed on the floor above the console the interpretation of mechanisms but also provides accurate kinetic data at the early stages of reactions. The increased penetration also leads to a better threedimensional understanding of metallographic structures, a feature that has been used to advantage at Imperial College for the study of corrosion and stresscorrosion morphologies developed in certain gold alloys.

The new microscope is massive by conventional standards and extends over thiree floors of the

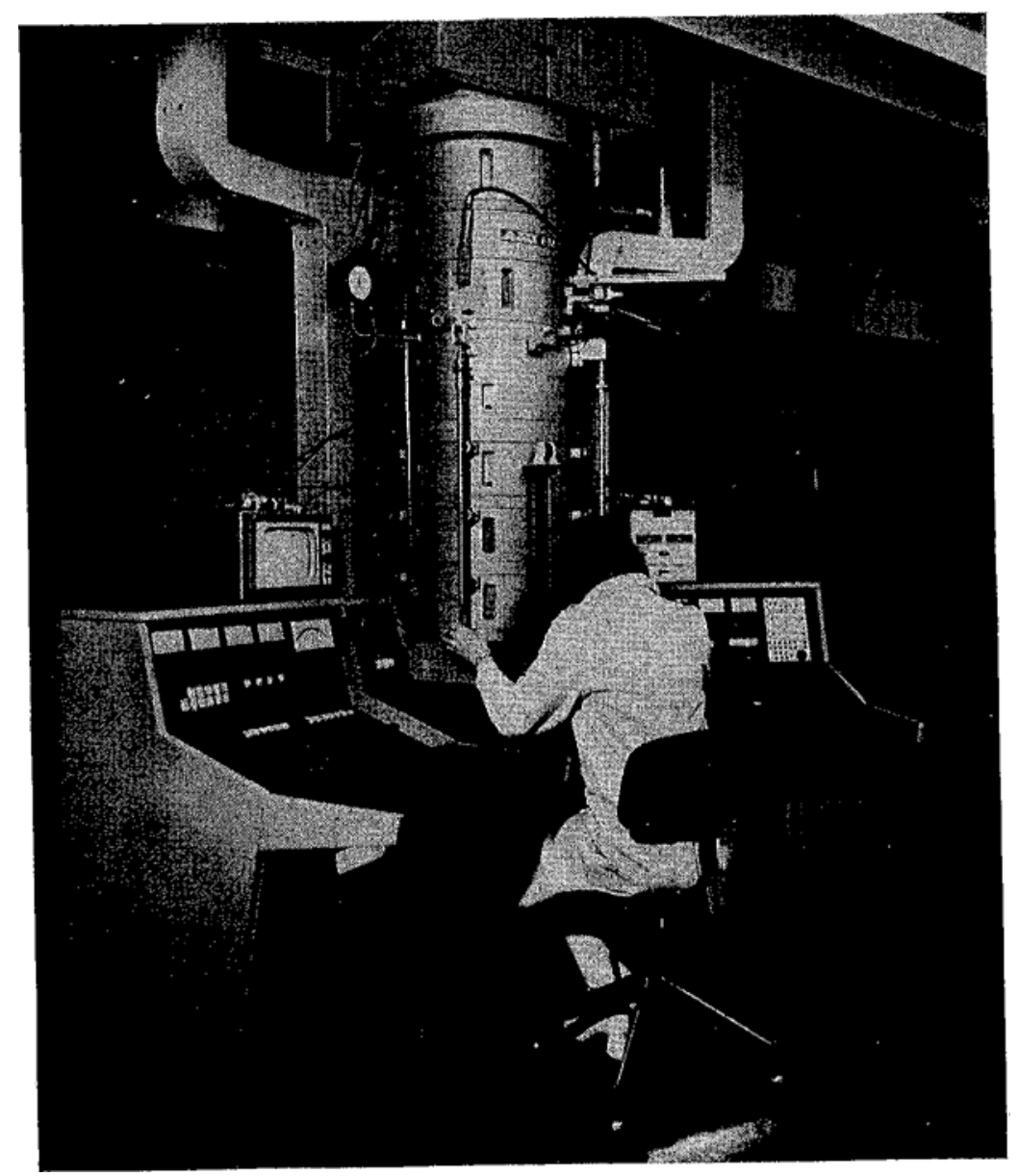


Fig. 2 Gold-nickel alloys can decompose on ageing by a cellular precipitation reaction. This transmission electron micrograph shows the nucleation and early stages of growth of this transformation from grain boundaries with alternate lamellae of nickel. rich (light) and gold-rich (dark) phases clearly visible. $\times \mathbf{4 8 , 0 0 0}$

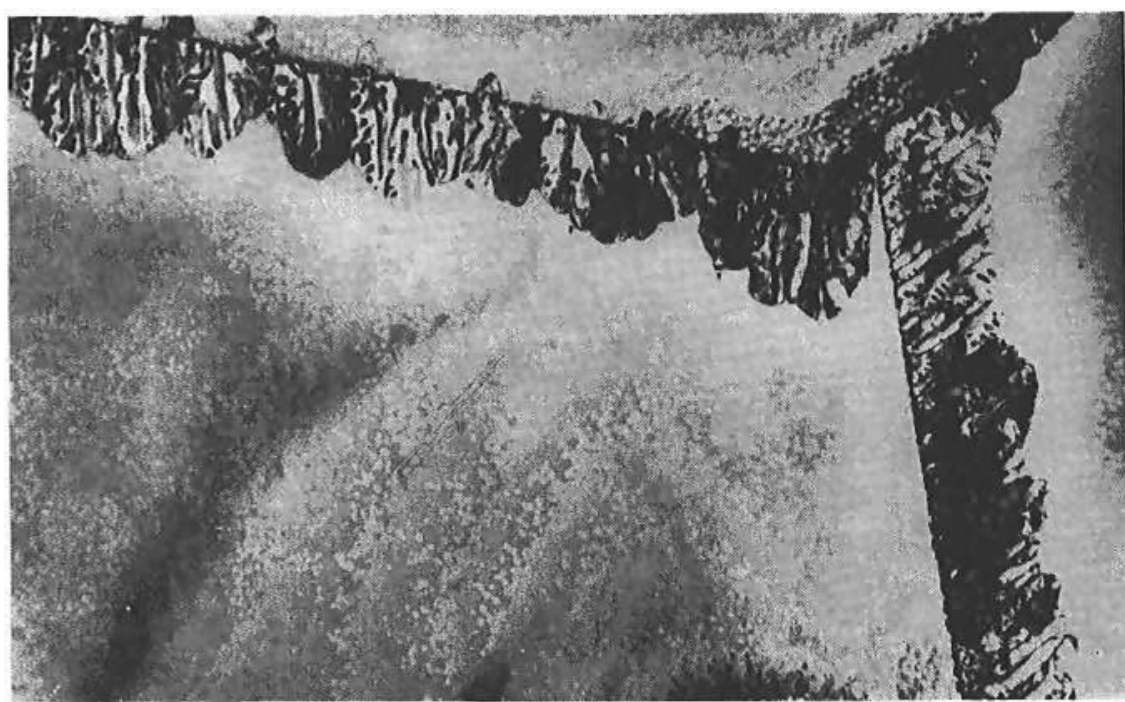

Metallurgy Department. The million volt accelerator and Cockcroft-Walton generator are housed on the middle floor and the upper floor contains the travelling crane used to dismantle the heavy pressure vessels which contain the high voltage insulating gas. The photograph in Figure 1 shows only the lower floor level which contains the microscope console mounted on its heavy anti-vibration block. In principle, the design of the column is similar to that of a conventional instrument except that the high energy of the electron beam necessitates special precautions against leakage of $\mathrm{X}$-rays. Radiation shielding is accomplished by using a large diameter column and installing depleted uranium collars and lead castings at critical points. The final image screen is viewed safely through an eleven inch thick lead glass window.

The energy of the electrons in the microscope is sufficiently high to cause radiation damage in certain specimens. This feature is especially useful for simulating the damage incurred by reactor materials and does indeed form one important application of high voltage microscopes. It is, however, an undesirable effect when performing in situ experiments because the damage may result in unusual reaction behaviour. Fortunately, because the threshold accelerating voltage for displacement damage in metals increases with atomic number, gold and its alloys can be studied without damage at much higher operating voltages than most metals. The threshold voltage for gold itself is thought to be about $1100 \mathrm{kV}$.

\section{Cellular Decomposition}

One in situ study currently under way with the instrument involves observation of cellular decomposition of nickel-gold alloys. The object of these experiments is to determine the mechanism by which gold and nickel in the solid solution separate to form a lamellar dispersion of gold-rich and gold- depleted phases. This reaction nucleates on grain boundaries and grows into the surrounding grains until complete transformation has occurred. Using an accurately calibrated hot stage, the growth rate can be determined at temperature by taking a series of micrographs at known intervals of time. Figure 2 shows the advancing interface after ageing for five minutes at $525^{\circ} \mathrm{C}$ and the alternate lamellae of goldrich (dark) and nickel-rich (light) phases can clearly be seen.

\section{Localised Chemical Analysis}

A new technique for local chemical microanalysis in thin foils of certain crystalline materials has been

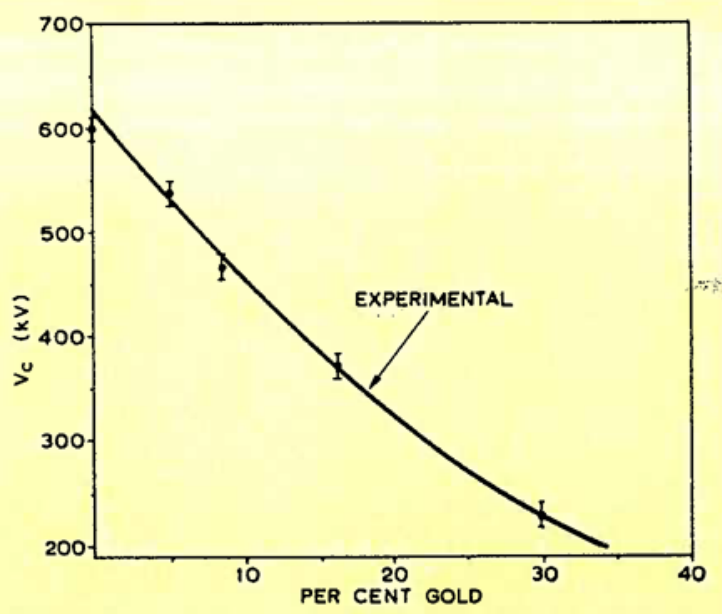

Fig. 3 For all crystalline materials there is a particular value of accelerating voltage in the HVEM at which there is a minimum in the diffracted intensity of certain Bragg reflections. This graph shows the variation of this voltage (the critical voltage) as gold is added to nickel. Small areas of unknown composition in nickel-gold alloys can thus be analysed if the critical voltage is determined locally in these regions 


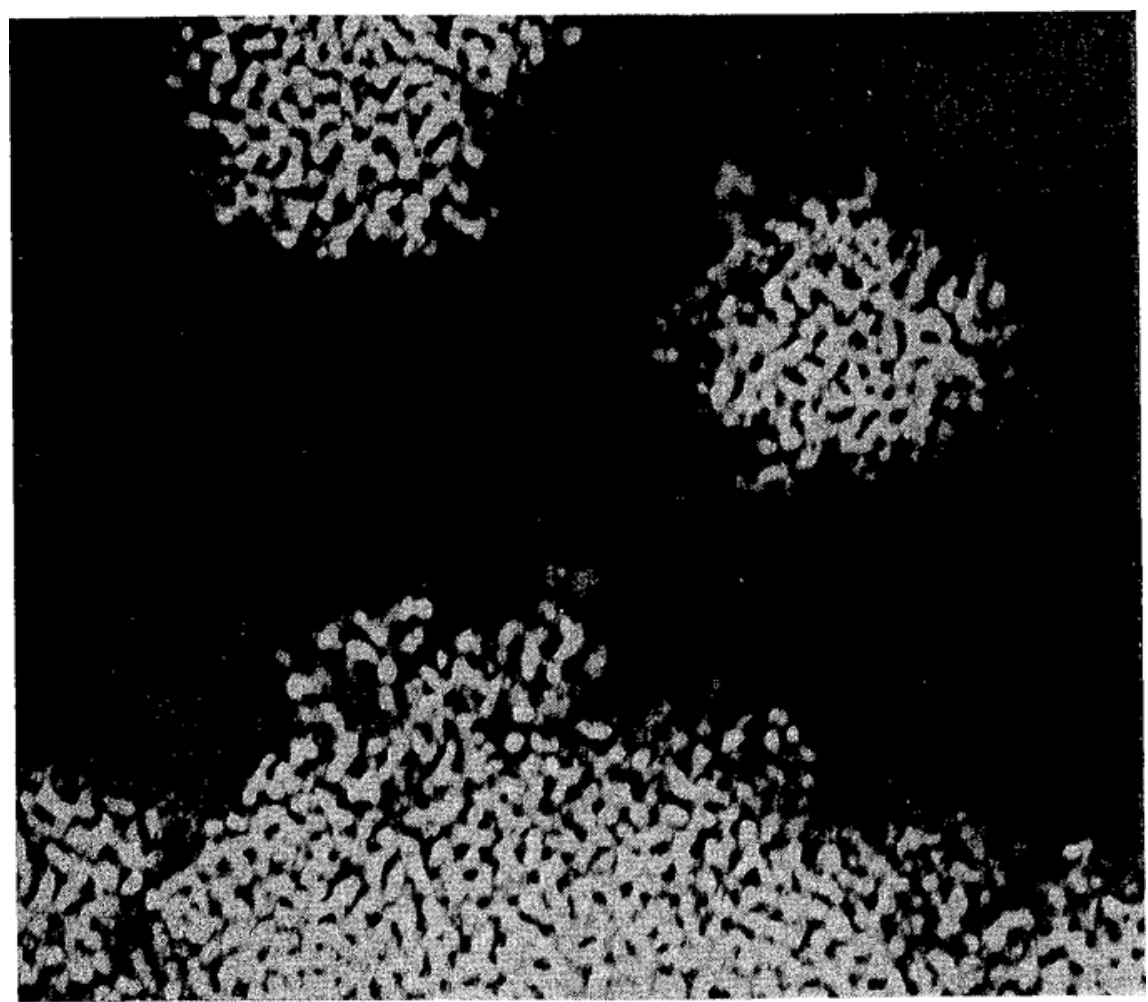

Fig. 4 A corrosion sponge colony formed in a nickel-30 atomic per cent gold alloy exposed for 20 seconds to a solution containing $10 \mathrm{mg}$ $\mathrm{FeCl}_{3}$ per 100 ce $\mathrm{H}_{2}$ o. The colony is formed by the repeated branching of corrosion tunnels (about 100 atoms in diameter) emanating from a single nucleation site on the alloy surface. The arrow indicates an island of the alloy matrix which has been isolated by the tunnelling reaction.

$\times 110,000$

pioneered at Imperial College using the high voltage electron microscope. This technique relies on the fact that at critical values of the electron accelerating voltage, the intensities of certain reflections scattered by the crystal are zero. In alloys, the value of this accelerating voltage (the critical voltage) depends on the kind of atom present and can be used to determine the alloy composition. The accuracy of the technique is greatest in alloys whose constituent elements differ greatly in their ability to scatter electrons. This is often the case for gold alloys containing base metals.

Figure 3 shows an example of a calibration curve relating the critical voltage $\left(V_{c}\right)$ to the gold content of a series of nickel-gold alloys. Using this curve it is possible to determine the composition of regions as small as $2000 \AA$ in diameter in any electron-transparent region of a microscope specimen. The technique has already been used to measure the changes in composition of nickel-rich precipitates during the early stage of their precipitation in a gold-nickel alloy.

\section{Corrosion and Stress-corrosion}

If gold alloys are exposed to environments which dissolve only the less noble components it would be expected that dissolution would cease as soon as the gold accumulates to cover the surface. In fact, this is only true if the noble metal exceeds a certain concentration known as the parting limit. Alloys less noble than this can dissolve very rapidly to form what appears to be a sponge-like mass of the noble metal. The true morphology of this product can only be revealed in the electron microscope because the scale of the porosity in the sponge-like structure approaches atomic dimensions, as can be seen in Figure 4. This is a high voltage micrograph showing the microstructure of a single corrosion sponge colony in a thin film specimen of a nickel-30 atomic per cent gold which has been exposed for 20 seconds to a solution containing $10 \mathrm{mg} \mathrm{FeCl}$ per $100 \mathrm{cc} \mathrm{H}_{2} \mathrm{O}$.

Several facts have emerged from detailed examination of corrosion sponge morphology.

A sponge colony is formed by the repeated branching of corrosion tunnels emanating from a single nucleation site on the alloy surface.

The nucleation site is rarely at a dislocation but can be an antiphase boundary junction in ordered alloys.

The diameter of the tunnels depends on the concentration of the noble constituent and typically ranges from 40 to 350 atomic diameters.

In the more concentrated alloys the noble constituent which is rejected on the surface of the tunnels tends to agglomerate in the form of particles.

The sponge structure is usually self-rupturing under the action of shrinkage stresses. This effect is important because it reduces the diffusion path of the electrolyte to the corrosion front and thereby speeds up the dissolution.

Based on these results, a theory has been developed that explains the variation of tunnel diameter with alloy composition. In this theory the stability of the 
tunnel dissolution front is explained by the geometrical requirement that the rate of accumulation of unreactive atoms on a receding singly curved surface (i.e. cylindrical tunnel walls) is greater than that on a receding doubly curved surface (i.e. hemispherical tunnel base). Consequently, the walls of a growing corrosion tunnel become protected by unreactive atoms before the base of the tunnel, thus establishing the basic condition for stable tunnel growth. The tunnel-type dissolution enables most of the base metal to be removed directly from the alloy surface. Contrary to the results of X-ray studies, no evidence was found for the bulk diffusion of the base metal to the surface over the distances claimed.

Tunnel corrosion has also been observed to nucleate at active slip steps and at grain boundaries, i.e. regions which are not protected by a gold surface layer. Furthermore, sponge-like corrosion structures which develop from these regions are found to fracture very easily in stressed specimens and ultimately to develop into recognisable stress corrosion cracks. Thus, the present work appears to have established a link between the stress corrosion of gold alloys containing base metals and their tendency toward micro-tunnel corrosion.

\section{The Gold Content of Sea-water}

\section{ITS EXTRACTION AN UNREALISABLE DREAM}

\section{F. H. Lancaster}

Chamber of Mines of South Africa, Johannesburg

The great increase recently in the price of gold has inevitably caused people to examine the possibility of recovering gold from deposits or sources which are not economic at the official price of gold.

One of these low-grade possible sources of gold is the sea, which has been described as a dilute solution of almost everything! Its volume, $1.37 \times 10^{21}$ litres, is such that at the minute concentrations at which it occurs the total amount of gold in the sea could be of the order of 6 million tons, but the problem is, of course, the great volume of water that would have to be processed in order to extract gold in any worthwhile amount.

The existence of gold in the ocean has been known for a hundred years; the first officially recorded report of its gold content was made in 1872 by Edwards Sonstadt (1), who reported the gold concentration. to be 65,000 micrograms per cubic metre.

Following Sonstadt, several investigators published the results of studies into the gold content of seawater, while a number of patents were granted for processes for recovering gold from the sea. The most determined attempts were made by Fritz Haber, the German chemist and Nobel Prize winner, who after the First World War entered upon an extensive programme of research into the recovery of gold from sea-water with the object of paying Germany's war debts. Haber (2) found the concentration of gold to be much less than he had expected, seldom exceeding $0.001 \mathrm{mg}$ per ton of sea-water. After ten years of work Haber came to the conclusion that gold could not be extracted economically from the sea. The average value of the gold concentration, Haber concluded, was about $0.04 \mathrm{mg} /$ ton.

Since Haber's researches much time and effort have been spent on the development of methods for extracting gold from the sea. A process which it has been claimed could be used is an ion flotation process developed by Professor Felix Sebba (3) of the University of the Witwatersrand. A review by North
(4) of the patents granted during a 75-year period showed that, except for the recovery of magnesium metal from sea-water, there has been no important commercially successful operation by which metal or metals are recovered from the sea as a sole or primary product. Recently J. B. Rosenbaum and his colleagues of the United States Bureau of Mines (5) concluded that not only is there at present no known procedure for the economic recovery of gold but that there is no process on the horizon which can be used for this purpose.

Rosenbaum and his colleagues, who used radiotracers to check on a solvent extraction-atomic absorption method, obtained a gold level of about 11 parts per $10^{12}$, which agreed closely with the results of previous analyses in which ion exchange and neutron activation methods were used.

At the then ruling price of gold this content of gold would have represented a value of 0.001 cent (U.S.) per ton of sea-water, and as Rosenbaum concluded, even if regional differences in the gold content of the oceans were to reveal localities containing 50 times the 11 parts per $10^{12}$ level, the increased value of 0.05 cent (U.S.) per ton would still fall far short of that needed for economic exploitation.

The alchemists dreamed that gold could be obtained by the transmutation of lead. The more recent dream that gold might be obtained from the sea seems equally unrealisable in practice.

\section{References}

1 E. Sonstadt, Chem. News, 1872, 26, 159

2 F. Haber, "Das Gold in Meerwasser," Zeit. angew. Chem., 1927, 40, 303-314

3 F. Sebba, "Ion Flotation," Elsevier, 1962

4 O. S. North, "Patents Reveal Persistent Efforts to Recover Gold from Sea Water," Eng. Min. F., 1966, 167, (9), 195-201

5 J. B. Rosenbaum, Joan T. May and J. M. Riley, "Gold in Sea Water - Fact or Fancy," Paper presented at 98th AIME Conference, Washington, D.C., February 1969 